\title{
Hungarian demonstratives in contrastive contexts
}

Enikő Tóth

Department of English Linguistics, University of Debrecen, Hungary

https://doi.org/10.36505/ExLing-2019/10/0051/000413

\begin{abstract}
This paper presents the results of corpus queries and a subsequent questionnaire study exploring the exophoric use of four Hungarian demonstratives ez/az. 'this/that' and emez/amaz 'this/that other one' in contrastive contexts. Concordance analysis revealed that the aforementioned four demonstratives often occur in various patterns, such as $e z_{-}$ amaz. Findings of the questionnaire study showed that in contrastive contexts, where two objects are placed either within or out of arm's reach in front of the speaker and addressee in table-top space on the sagittal axis, the acceptability of the emerging contrastive patterns does not depend on relative distance. This means that speaker proximity can be overridden by contrastive function in Hungarian.
\end{abstract}

Key words: demonstratives, contrastive, exophoric, Hungarian

\section{Introduction}

Hungarian has a two-way speaker-proximal versus distal system of demonstratives, comprising proximal eq 'this' and distal az 'that'. However, there are two other, less frequently used demonstratives, proximal emez ' this one nearby/this other one' and distal amaz. 'that one over there/that other one', which are either assumed to make a more finer distinction within near and far, or to have a reinforcing role (Laczkó 2012). The aim of this paper is to explore a novel, previously neglected contrastive use of emez/amaz, relying on corpus based findings and experimental data.

Crosslinguistically, exophoric contrastive uses of demonstratives, such as $I$ find this sofa nice, but that one is ugly. (cf. Levinson 2004), have been studied for example by Meiro and Terrill (2005), who showed that the use of demonstratives is different in contrastive and non-contrastive contexts in Tiriyó and Lavukaleve. Further elicitation studies revealed that in contrastive contexts proximity is often neutralized across languages (see Wilkins 1999 and Levinson 2018 for details). In the case of Hungarian, Tóth et al. (2014) compared the use of the more frequent demonstratives (eq/az) in neutral vs. contrastive contexts (Eqt kérem. 'I want this.' vs. Ezt a dobozt vidd le a pincébe, azt viszont hagyd a helyén. 'Take this box down to the cellar, but leave that one where it is.' Laczkó 2012: 296). It was shown that while relative distance from the speaker is crucial in neutral contexts, in contrastive contexts, when the objects being referred to are both close to the speaker, the distal term (az) is used in a significantly higher proportion. The aim of this study is to widen the scope of investigation and to examine the use of emez/amaz in contrastive contexts.

ExLing 2019: Proceedings of $10^{\text {th }}$ International Conference of Experimental Linguistics, 25-27 September 2019, Lisbon, Portugal 


\section{Corpus findings}

First, frequency queries were run in the Hungarian National Corpus, which found 728 and 2331 tokens of emez and amaz, respectively. Concordance analysis revealed that each of the four demonstratives can create a contrast with other referring expressions. There were altogether 943 contrastive examples including emez or amaz in the corpus. emez/amaz typically appeared in contrastive contexts in patterns where one proximal and one distal term are combined. A relevant example is the following: $E_{z}$ ide az ágy alá, amaz meg a polcra - jó lesz karácsonyra. 'This comes here below the bed, that other one goes to the shelf - for Christmas'. ez-emez, az-amaz might also surface in the same utterance, but these patterns were not so frequent. These findings are in line with cross-linguistic data (cf. Wilkins 1999, Maes \& de Rooij 2007). Table 1 shows the relative frequency distribution of the patterns emerging.

Table 1. Relative frequency of patterns including emez/amaz in HNC.

\begin{tabular}{|l|l|l|}
\hline \hline pattern & number & relative frequency \\
\hline amaz-amaz & 1 & $0.1 \%$ \\
\hline az-emez & 35 & $3.7 \%$ \\
\hline az-amaz & 227 & $24 \%$ \\
\hline emez-amaz & 141 & $15 \%$ \\
\hline emez-emez & 16 & $1.7 \%$ \\
\hline ez-emez & 27 & $2.9 \%$ \\
\hline ez-amaz & 496 & $52.6 \%$ \\
\hline \hline
\end{tabular}

\section{Questionnaire study}

The most frequent five patterns in Table 1 served as input to an online questionnaire study. The question to be addressed was whether the acceptability of the patterns depends on the relative distance of the objects being referred to from the speaker, i.e. whether the contrastive function of the patterns can overwrite the role of proximity. 55 subjects saw photos depicting the position of two speakers (sitting next to each other) with respect to two objects placed in table-top space on the sagittal/away axis. One of the referents was objectidentifiable, the other was referred to by a demonstrative pronoun. Participants provided acceptability judgements of contrastive utterances exemplifying one of the patterns on a 5 point Likert scale. Each target utterance contained two demonstratives (i.e. one pattern was presented), such as Az a fekete esernyö sokekal strapabiróbb modell, mint emez: "That black umbrella is sturdier than this other one.' The referents were easily identifiable, and there was no difference between the objects regarding salience.

The questionnaire contained 20 target items and 10 fillers. Two factors were examined in a $2 \times 5$ design: DISTANCE: peripersonal (within arm's reach) vs. 
extrapersonal (out of arm's reach) (see Kemmerer 1999), and TYPE OF CONSTRUCTION: eq-emez, eq-amaz, az-amaz, az-emez, and emez-amaz: Overall results are presented in Figure 1.

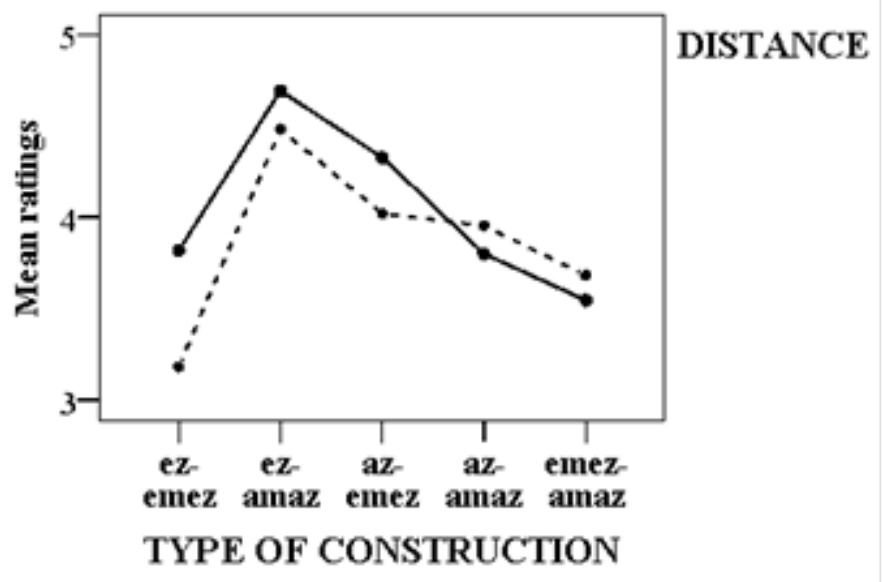

Figure 1. Overall results.

eq-amaz received the highest average ratings in both distance conditions and this pattern was also the most frequent one in the Hungarian National Corpus. There was only a marginal effect of DISTANCE, this factor is only responsible for $15 \%$ of overall variability: $\mathrm{F}(1,54)=9.519, \mathrm{p}<0.05, \eta^{2}=0.15$. There were significant differences in between the peripersonal and extrapersonal conditions only in the case of eq-emez, and az-emez, both received significantly higher ratings in the peripersonal condition. Regarding ez-emez this is not surprising, since a combination of two proximals is preferred when referring to entities that are within arm's reach from the speaker. Considering az-emez, ar, a distal demonstrative creates a contrast with an entity that is closer to the speaker within peripersonal space.

In the case of the remaining patterns, distance is not a decisive factor, i.e. in contrastive contexts distance as a factor can be overridden; the patterns in question are equally acceptable both in the peripersonal and extrapersonal conditions. The findings reinforce the results of the previous study (Tóth et al. 2014) on the contrastive uses of $e z / a z$, and are in line with cross-linguistic results. Namely, it has been shown that in contrastive contexts proximal demonstratives are also acceptable when they refer to objects that are far from the speaker, while distal terms are acceptable when the referents are within arm's reach.

A more substantial main effect of TYPE OF CONSTRUCTION was also found, $\mathrm{F}(1,51)=22.533, \mathrm{p}<0.001, \eta^{2}=0.64$. eq-amaz, the most frequent pattern in the corpus study, received significantly higher ratings then each of the other 
patterns, while the least frequent pattern, eq-emez, got the lowest ratings. There was also a significant interaction between the two variables.

To conclude, the results of the two studies report similar findings. Each of the Hungarian demonstratives (ez/az, emez/amaz) appears in contrastive contexts, and the findings of the rating task revealed that speaker proximity can be overridden by contrastive function in Hungarian.

\section{Acknowledgements}

The Project no. 111918 (New approaches in the description of the grammar of Hungarian pronominals) has been implemented with the support provided from the National Research, Development and Innovation Fund of Hungary.

\section{References}

Kemmerer, D. 1999. 'Near' and 'far' in Language and Perception. Cognition 73, 35-63.

Laczkó, K. 2012. Spatial deixis and demonstrative pronouns in Hungarian. In Hart, C. (ed.) Selected Papers from UK-CLA Meetings, 289-301, http://ukcla.org.uk/proceedings

Levinson, S. C. 2004. Deixis. In Horn, R., Ward, R. (eds.) The Handbook of Pragmatics, 97-121, Oxford, Blackwell Publishing.

Levinson, S. C. 2018. Introduction: Demonstratives: Patterns in Diversity. In Levinson, S. C., Cutfield, S., Dunn, M. J., Enfield, N. J., Meira, S. (eds.) Demonstratives in Cross-Linguistic Perspective, 1-42. CUP.

Maes, A., de Rooij, C. 2007. (How) Do demonstratives code distance? In Branco, A. McEnery, T., Mitkov, R., Silva, F. (eds.) Proc. of DAARC 2007, 83-89, Lagos Portugal, Centro de Linguistica da Universidade de Porto.

Meira, S., Terril, A. 2005. Contrasting contrastive demonstratives in Tiriyó and Lavukaleve. Linguistics 43, 1131-1152.

Tóth, E., Csatár, P., Banga, A. 2014. Exploring Hungarian and Dutch gestural demonstratives. In Veselovská, L., Janebová, M. (eds.) Complex Visibles Out There. Proc. of the Olomouc Linguistics Colloquium 2014: Language Use and Linguistic Structure. 607-625, Olomouc: Palacký University.

Wilkins, D. 1999. Eliciting contrastive use of demonstratives for objects within close personal space (all objects well within arm's reach). In Wilkins, D. (ed.) Manual for the 1999 Field Season. 25-28, Nijmegen: Max Planck Institute for Psycholinguistics. 